\title{
'Be Cool!': Emotional costs of hiding feelings in a job interview
}

\section{Monika Sieverding}

Institut für Psychologie, Ruprecht Karls Universitæt Heidelberg, Hauptstr. 47-51, 69115 Heidelberg, Germany. monika.sieverding@psychologie.uni-heidelberg.de

The goal of this research was to study display rules and emotional suppression in an employment interview. Participants, 74 graduating university students, were told that their videotaped performance in a simulated job interview would be evaluated by personnel experts. In a post-interview questionnaire, participants were asked about the display rules influencing their behavior in the interview. They were also asked whether they had tried to suppress or hide (negative) emotions during the interview. More men than women stated that they had tried to hide or suppress their feelings; these participants were classified as (emotion) suppressors. Participants who stated that they had not tried to hide or suppress their feelings during the interview were classified as nonsuppressors. The validity of self-reported suppression was supported by the external evaluations of two judges, who observed less nonverbal expressiveness (hand to head movements) in suppressors of both sexes and less anxiety in female suppressors. Suppressors were evaluated as more competent than nonsuppressors. In women, but not in men, emotional suppression was associated with increased self-reports of depressed state in the post-interview questionnaire.

\section{Introduction}

T here are many situations in daily life in which it is culturally unacceptable to express emotions openly. Recipients of unappealing birthday presents often try to hide their disappointment, for example, and children learn to hide their feelings of pity or interest toward people with disabilities (Saarni, 1979). It is often particularly important to suppress negative feelings during interactions with people in positions of power. Fortunately, the spontaneous expression of emotion can be controlled deliberately and is governed to some extent by situative norms. Ekman and Friesen (1975) pointed to the existence of social display rules that prescribe who should/may (or should not/may not) show which emotion to whom and in which situation. Situative constraints and display rules can both either facilitate or inhibit emotional expression. The goal of the present research is to investigate the role of display rules in employment interviews.

\subsection{Impression management (IM) in employment interviews}

The employment interview is a common and popular procedure for gathering information about job applicants (Posthuma, Morgeson, \& Campion, 2002); it is part of the hiring process for virtually all jobs. Research has demonstrated that the subjective impression of an applicant's interview performance is an important predictor of interviewer's evaluation (Gilmore \& Ferris, 1989; Rynes \& Gerhart, 1990). Applicants use several assertive IM tactics to influence the interviewer's perception of them and to present a positive image (Stevens \& Kristof, 1995). One focus of research has been to identify which IM tactics applicants use during job interviews (e.g., personal stories) and to analyze which IM tactics are predictors of interviewers' evaluations and actual interview outcomes. A laboratory study found that use of self-promotion (compared with other-focused) tactics was related to higher 
evaluations and more job offers (Kacmar, Delery, \& Ferris, 1992). In a field study, Stevens and Kristof (1995) found that applicants relied heavily on assertive IM tactics and that applicant self-promotion and fit with organization tactics were significant predictors of positive interviewer evaluations and actual job offers. Higgins and Judge (2004) found that ingratiation had a positive effect on recruiter hiring recommendations. Taken together, research has shown that IM behaviors such as self-promotion are related to more positive evaluations of job applicants (Posthuma et al., 2002). To date, however, most research examining IM tactics in the context of employment interviews has concentrated on the use of verbal tactics. Display rules governing emotional expression in the context of job interviews have not previously been the subject of explicit study.

\subsection{Anxiety in employment interviews}

Anxiety is an inherent part of the job interview process (Young, Behnke, \& Mann, 2004). The employment interview is a highly evaluative situation, the interviewer is typically a stranger, and interviews are generally not under the applicant's control (McCarthy \& Goffin, 2004). The open display of anxiety in interview situations can entail negative social sanctions, however. In a field study, McCarthy and Goffin (2004) found a negative relationship $(r=-.49)$ between interviewer-rated applicant anxiety and interviewer-rated interview performance: applicants who made an anxious impression were rated as less successful. Interestingly, interviewerrated anxiety was only weakly related to one of five interviewee-rated anxiety scales; associations with the other four scales were not significant. This result shows that felt emotion and observed emotion do not necessarily covary closely and can be interpreted as indicating that (some) applicants are able to hide (some of) their anxiety in the job interview. Another study found that highly anxious individuals were less likely to be given a second interview than were less anxious individuals (Cook, Vance, \& Spector, 2000). The authors concluded that high-anxious individuals tend to have a less favorable self-presentational style, appearing insecure and apprehensive in interview situations.

\subsection{Gender differences in emotional expression}

Prior research has quite consistently shown that women tend to be more emotionally expressive than men as well as more expressive of fear (Brody \& Hall, 2000; Hall, 1990; Kring \& Gordon, 1998). The higher expressiveness of women has been explained by differences in early socialization in gendered cultures (Maccoby, 1998) and by social role theory and gender-specific norms in emotional interactions (Grossman \& Wood, 1993). During socialization, boys and girls learn different rules for the expression of emotion. Boys learn to conceal their feelings, especially of vulnerability, whereas girls learn to express their feelings more freely (Brody, 2000; Brody \& Hall, 2000). In a questionnaire study, Timmers, Fischer, and Manstead (1998) asked male and female students about their (probable) emotions and expression of emotions in hypothetical situations that were described in short vignettes. Men were more likely than women to report that they would not show any emotion when disappointed, sad, or afraid, whereas women were more likely than men to report that they would overtly express these emotions verbally or nonverbally (e.g., by crying). The authors interpreted men's greater inclination to hide their sadness, fear, and disappointment as reluctance to display signs of powerlessness and to be judged as 'emotional.'

\subsection{Consequences of emotional suppression}

The regulation of emotion, and especially its suppression, is known to have physiological, social, affective, and cognitive consequences (Gross, 2002). Influenced by early psychosomatic theorizing (Alexander, 1939), research initially focused on the physiological consequences of inhibiting emotions. Most studies support an inverse relationship between emotional expression and physiological reactivity to emotional stimuli. Participants with suppressed or inhibited emotional expression were at the same time physiologically more active than expressive participants (Traue \& Pennebaker, 1993). In terms of the cognitive consequences of emotional suppression, several studies have shown that suppression reduces memory for social information, which was interpreted as an indicator of increased cognitive load (Butler, Egloff, Wilhelm, Smith, Erickson, \& Gross, 2003; Richards \& Gross, 1999, 2000).

The focus of the present article is on the psychological consequences of emotional suppression in a selection situation. Hochschild (1983) postulated that the regulation of emotions is an important part of many work roles ('emotional labor'). Organizations have the implicit rule that positive emotions should be displayed whereas negative emotions should not (Diefendorff \& Richard, 2003). Several studies have examined the emotional consequences of hiding (negative) feelings in the work domain, for example, among flight assistants (Hochschild, 1983). A recent study involving a call center simulation found that participants who were instructed to show positive emotions ('enthusiasm') and to hide negative emotions ('frustration') reported more post-simulation exhaustion than participants who were not given such display rules (Sideman Goldberg \& Grandey, 2007). Is the suppression of emotion in job 
interviews also associated with emotional costs? Anderson (2004) defined 'negative psychological effects' (NPEs) as encompassing the range of situations in which exposure to the selection process has (unintentionally) negative effects on applicants' psychological well-being or mental health. Initially, it was thought that selection methods would have negative impacts primarily on rejected applicants. Indeed, in a longitudinal study of assessment center candidates, Fletcher (1991) found that, relative to successful candidates, unsuccessful candidates showed decreased job mastery and job involvement and increased depressed state at work. However, a more recent longitudinal study of NPEs in assessment center participants also found slight decreases in the well-being and positive affect of successful participants (Anderson \& Goltsi, 2006). The question thus arises whether the use of IM tactics, especially the suppression of negative feelings, in job interviews has negative effects on the psychological well-being of the job applicants.

\subsection{The present research}

Although numerous studies have investigated assertive verbal IM techniques in job interviews, little is yet known about the role of emotional expression or suppression in this context. Do applicants feel a pressure to hide their feelings of anxiety in interview situations? The present research hypothesized that display rules govern the expression of emotions, especially anxiety and insecurity, in job interview situations.

Hypothesis 1: Emotional expression in job interviews is governed by display rules. Most job applicants feel compelled to hide negative feelings.

A second goal of the study was to examine gender differences in emotional suppression in job interviews. Because men are more socialized to hide their feelings of fear and insecurity, they were expected to be more strongly motivated than women to hide these feelings in an interview situation.

Hypothesis 2: Men are more likely than women to hide negative feelings such as anxiety during job interviews.

A further goal was to investigate whether suppression of negative feelings has positive consequences on external judges' evaluations of job applicants. Previous research has shown that higher anxiety of applicants is associated with lower success in employment interviews. Research has also demonstrated that external judges do not necessarily pick up on applicants' selfrated anxiety. Applicants who succeeded in hiding their negative feelings (especially anxiety) were therefore expected to be evaluated as more competent by external judges.

Hypothesis 3: Applicants who successfully hide negative feelings in job interviews are likely to be evaluated as more competent than applicants who do not succeed in hiding these feelings.

Finally, the emotional consequences of hiding feelings were investigated. Research has shown that suppressing feelings has physiological as well as cognitive costs. Suppression of negative feelings was therefore expected to have psychological costs, reflected in increased negative affect immediately after the job interview.

Hypothesis 4: Applicants who hide negative feelings in a job interview situation (suppressors) report more negative affect after the interview than do applicants who do not hide these feelings (nonsuppressors).

\section{Method}

\subsection{Overview}

A job selection situation comprising an interview and other tasks was simulated in the laboratory. Participants (74 men and women) were told that their performance would be evaluated by external personnel experts. Self-reports on emotional state were obtained in a pre-interview questionnaire, immediately after the job interview, and in a post-interview questionnaire (after completion of the whole selection procedure). Facial expressiveness and job interview performance were evaluated by external ratings of video recordings. In the post-interview questionnaire, participants were asked whether their behavior was influenced by display rules and whether they had actively tried to hide their feelings during the interview. ${ }^{1}$

\subsection{Participants}

Study participants were 74 students $^{2}$ ( 37 female) from various departments of the Free University of Berlin, most of whom were approaching the end of their degree program and likely to enter the job application and interview process in the near future. Some participants ( 4 men and 7 women) had already graduated. The participants were between 22 and 34 years of age $(M=26.4, S D=2.7)$. They received 15 euros as compensation for their participation in the study. 


\subsection{Procedure}

The investigation was conducted in the laboratory of the Institute for Medical Psychology at the Free University of Berlin. Each session was conducted individually by a female experimenter; the instructions were prerecorded and presented via a cassette player. To begin, participants were questioned about their professional goals and asked to indicate an attractive position for which they would like to apply. They were then requested to act as though they were applying for this position during a simulated job selection situation. Several tasks often used in the job selection process were administered (a written performance test, a verbal self-presentation of the applicant's qualifications, and a job interview). The present research focuses on just one of these tasks: the job interview. In order to standardize the study conditions and to eliminate social interaction effects, the interview questions were prerecorded (by a male voice) and presented via audiocassette. Ten questions typical for job interviews in Germany, especially for stressful interviews, were posed (e.g., 'What qualifies you for this position?,' 'What are your weaknesses?'). Participants were asked to imagine that they had been invited to a job interview on the basis of a written application and that they were now sitting in front of the interview panel. They were given $1 \mathrm{~min}$ to answer each question and their answers were recorded on video. Participants were asked to rate their emotional state in a pre-interview questionnaire (administered before the different tasks of the selection procedure), immediately after the job interview, and in a post-interview questionnaire (after completion of the whole selection procedure). In the post-interview questionnaire, participants were asked about their experiences during the job interview and whether their behavior had been influenced by display rules. Participants were assured that their self-reports of emotional states and experiences during the interview would not be part of the evaluation process by the external experts.

\subsection{Measures}

\subsubsection{Self reports}

2.4.1.1. Subjective state. A modified version of the questionnaire on subjective emotional state (Wallbott \& Scherer, 1991) was administered before the interview (pre-interview questionnaire), immediately after the interview, and in a post-interview questionnaire. Participants indicated on a 10-point scale from 'not at all' (0) to 'very well' (9) how well each of the following adjectives described their state during the preceding period: calm, aroused, relaxed, balanced, stressed, nervous, depressed, anxious, and successful. The affec- tive states 'anxious' and 'depressed' are of particular interest for the present research.

2.4.1.2. Display rules. In the post-interview questionnaire, participants were asked about the rules governing the expression of their feelings and expressive behavior: 'Was your behavior during the interview situation influenced by certain display rules? (Yes/No) If yes, by which rules?' A short explanation of display rules was given: 'Examples of display rules are being polite to your supervisor or showing joy over a birthday present.'

2.4.1.3. Hiding feelings. Participants were then asked if they had actively attempted to suppress or hide their (negative) feelings during the job interview: 'During the job interview, did you try to suppress or hide your feelings (e.g., anger, insecurity, anxiety, helplessness, etc.)?' Response options were 'no, not at all' (0), 'no, not really' (1), 'yes, a little' (2), and 'yes, a lot' (3). Participants were also asked to indicate which feelings they had tried to suppress or hide (open response). The number of feelings named ranged from 0 to 2 . There was a correlation of $r=.73$ between the number of feelings nominated and endorsement of the suppression item, which can be regarded as an indicator for the reliability of the self-report of suppression. The participants' self-reports in the post-interview questionnaire were used to divide them into two groups. Those who responded that they had tried to suppress or conceal their emotions 'a little' or 'a lot' were classified as (emotion-) suppressors $(n=36)$. Those who maintained that they had not tried to suppress or conceal their emotions 'at all' or 'really' were classified as nonsuppressors $(n=38)$.

\subsubsection{External evaluations}

2.4.2.1. Facial expressiveness. External judges assessed applicants' facial expressiveness on the basis of a video segment from the job interview (response to the question 'What are your weaknesses?'). Two female judges, a psychologist and a physician, who were blind to the hypotheses of the investigation, rated participants' nonverbal facial expressiveness on established expressiveness scales, defined and operationalized in accordance with studies on nonverbal behavior (Friedman, Hall, \& Harris, 1985; Herbeck, 1995; Riggio \& Friedman, 1983; Traue, 1989), with responses on a 10point scale from 'not at all' (0) to 'very much' (9). The 'emotional expressiveness' scale measures the liveliness of facial expression, whereas the 'neutral face' scale measures both the nonexpression of emotions and the nonexpression of nervousness or tenseness. The other rating scales assessed 'eye contact,' 'changes in position,' 'head movements,' 'hand to head movements,' 'tenseness,' and 'smiling.' Both judges evaluated all participants. After thorough training, interrater reliability as 
assessed by Spearman-Brown's correlation coefficients was high, ranging from $r=.88$ ('emotionally expressive') to $r=.99$ ('hand to head movements'). Ratings were thus averaged across the two judges.

2.4.2.2. Emotional state and performance. Following the assessment of nonverbal expressiveness without sound, the judges watched the video segment again with sound. They then evaluated how competently the participant responded to the question "What are your weaknesses?' on a scale from 0 'not at all competently' to 9 'very competently.' As a result of thorough training on this competence evaluation, ${ }^{3}$ interrater reliability was high $(r=.95)$. Finally, the judges gave an overall assessment of each participant ('The participant appears ...') on the same attributes as presented to the participants. The interrater reliability of the external assessment of anxiety was $r=.64$; that of the external rating of 'successful' was $r=.90$.

The competence ratings and the general evaluation of the participant as 'successful' were combined to give a single competence score (arithmetic mean of the two scores with possible values from 0 to 9). Internal consistency was high (Cronbach's $\alpha=.90$ ).

\subsubsection{Statistical analysis}

The number of participants who reported that their behavior in the interview had been influenced by display rules was determined. Gender differences in selfreported suppression (yes/no) were examined using a $\chi^{2}$ test. Two analyses were conducted to validate self-reported suppression: 2 (suppression/nonsuppression) $\times 2$ (male/female) MANOVAs were used to analyze external ratings of nonverbal expressiveness (eight scales) as well as external ratings and self-ratings of anxiety during the interview. Sex of participants was included as an independent variable in these analyses to test whether self-reported suppression had differential effects for external ratings of nonverbal expressiveness and anxiety in male and female participants. A first hierarchical regression analysis was conducted to predict the external evaluation of competence, with sex of participant and suppression (vs nonsuppression) entered in the first step and the sex $\times$ suppression interaction in the second step. A second hierarchical regression analysis was conducted to analyze potential effects of suppression on affective state after the interview. The criterion variable was the self-rating of depressed state in the post-interview questionnaire. As possible predictors, the pre-interview self-rating of depressed state was entered in the first step, sex and suppression (vs nonsuppression) were entered in the second step, and the interaction of sex $\times$ suppression was entered in the third step.

\section{Results}

\subsection{Display rules (Hypothesis 1)}

The majority of men $(29=78 \%)$ and women $(28=76 \%)$ stated that their behavior during the job interview was influenced by display rules. Examples of the display rules named by the participants are listed in Table 1 . These rules emphasize the importance of emanating self-confidence and assertiveness, displaying only positive emotions, and suppressing or concealing feelings of insecurity, nervousness, annoyance, or anxiety. The data therefore support Hypothesis 1, which states that the behavior of applicants in job interviews is influenced by display rules.

\subsection{Gender differences in self-reported emotional suppression (Hypothesis 2)}

More men than women stated that they had tried to suppress or hide emotions 'a little' or 'a lot' during the interview (see Table 2). Specifically, 23 men (62\%) and 13 women (35\%) were categorized as suppressors, and 14 men and 24 women as nonsuppressors. The gender difference was significant, $\chi^{2}(1, N=74)=4.4, p<.05$, confirming the hypothesis that men are more likely than

Table 1. Display rules for expression of emotions in job interviews

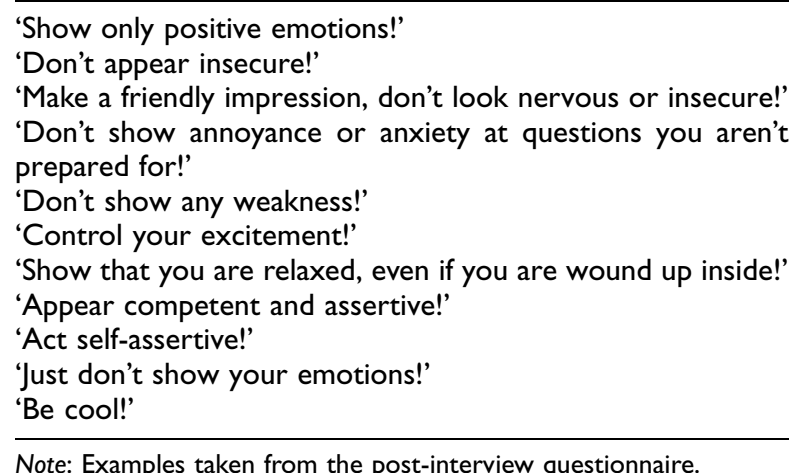

Note: Examples taken from the post-interview questionnaire.

Table 2. Gender differences in self-reported emotional suppression during the job interview

\begin{tabular}{|c|c|c|c|c|}
\hline & \multicolumn{2}{|c|}{ Men } & \multicolumn{2}{|c|}{ Women } \\
\hline & $n$ & $\%$ & $n$ & $\%$ \\
\hline No, not at all $(0)$ & 4 & 10.8 & 11 & 29.7 \\
\hline No, not really (1) & 10 & 27.0 & 13 & 35.1 \\
\hline Yes, a little (2) & 19 & 51.4 & 9 & 24.3 \\
\hline Yes, a lot (3) & 4 & 10.8 & 4 & 10.8 \\
\hline Nonsuppressors (0 and 1 ) & 14 & 37.8 & 24 & 64.8 \\
\hline Suppressors (2 and 3) & 23 & 62.2 & 13 & 35.1 \\
\hline
\end{tabular}

Note: $N=74$. Answers to the question 'During the job interview, did you try to suppress or hide your feelings (e.g., anger, insecurity, anxiety, helplessness, etc.)?' in the post-interview questionnaire. 
women to suppress or hide their (negative) emotions in a job interview. In response to the question of which feelings they had tried to suppress, both men and women named 'insecurity' far more frequently than any other emotion (16 of 23 men, 11 of 13 women). Other feelings nominated were excitement, helplessness, anxiety, and feelings of inferiority.

\subsection{External judges' evaluations of suppressors and nonsuppressors (validation of self-reported suppression)}

Is self-reported suppression of feelings validated by external evaluations of the participants' behavior? Did suppressors succeed in concealing their anxiety? This question was addressed by reference to the external judges' evaluations of the participants.

\subsubsection{Nonverbal expressiveness}

A $2 \times 2$ (sex $\times$ suppression) MANOVA with the external ratings of nonverbal expressiveness (eight scales) as the dependent variables revealed a main effect for suppression, $F(8,63)=2.2, p<.05$. Follow-up univariate tests revealed a main effect for suppression on 'hand to head movements,' $F(1,70)=5.6, p<.05$. Suppressors made fewer 'hand to head movements' than nonsuppressors $(M=.4, S D=.9$ vs $M=1.4, S D=2.2)$.

3.3.2. External ratings of anxiety as a function of selfreported suppression

A further $2 \times 2$ (sex $\times$ suppression) MANOVA was conducted with the self-evaluations and external evaluations of anxiety as dependent variables. The main effect for suppression was only marginally significant, $F(2,69)=2.7, p=.78$, whereas the main effects for sex and the sex $\times$ suppression interaction were both significant; sex: $F(2,70)=4.0, p<.05$; sex $\times$ suppression: $F(2,69)=4.1, p<.05$. As shown in Figure 1 , men's anxiety self-ratings were lower than women's, $F(1,70)=4.1, p<.05$; moreover, men were rated as less anxious by the two judges, $F(1,70)=5.2, p<.05$. In men, self-ratings and external ratings of anxiety did not differ significantly as a function of (self-reported) suppression. In women, however, suppression did make a difference: female suppressors had higher anxiety selfratings than did female nonsuppressors, $t(35)=-2.1$, $p<.05$. The opposite held for external ratings, with female suppressors being rated as less anxious than female nonsuppressors, $t(35)=2.7, p<.05$.

The external ratings therefore support the validity of participants' self-reports of suppression - more clearly for the female participants. The raters observed fewer hand to head movements in suppressors of both sexes and - in female participants only - less anxiety during the job interview in suppressors than in nonsuppressors.

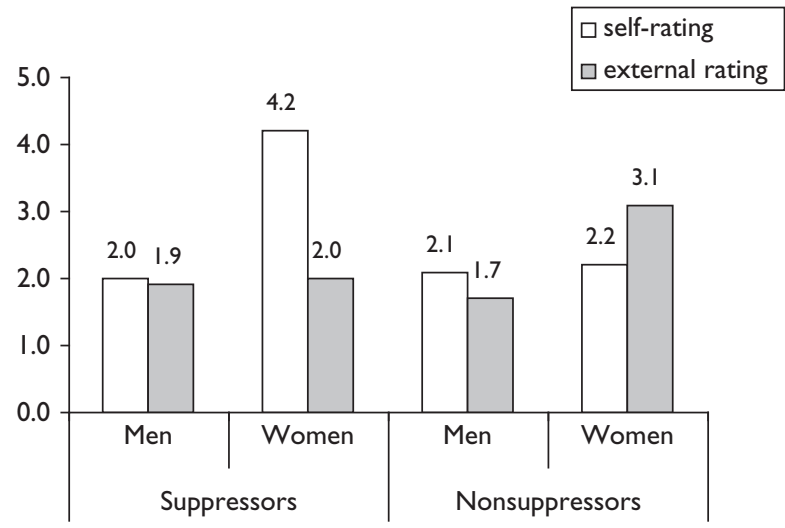

Figure 1. Self- and external ratings of anxiety during the job interview as a function of sex of participants and self-reported suppression; possible scores from 0 ('not at all anxious') to 9 ('very anxious').

\subsection{Consequences of hiding feelings I: Are suppressors evaluated as more competent than nonsuppressors? (Hypothesis 3)}

In a first step, correlations between the variables external evaluations of competence, sex of participant, and suppression were calculated. External evaluations of competence were significantly associated with selfreported suppression $(r=.24, p<.05)$ and marginally associated with sex of participant $(r=-.22, p=.066)$. In a second step, a hierarchical regression analysis was conducted with the external rating of competence in the job interview as the criterion variable. As potential predictors, sex of participant and self-reported suppression were entered in the first step and the sex $x$ suppression interaction was entered in the second step. The regression equation for the first step was significant, $F(1,73)=4.4, p<.05, R^{2}=.058, R_{\text {adjusted }}^{2}=.048$; inclusion of the interaction term in the second step did not significantly increase explained variance. Sex was not a significant predictor of external competence ratings; the effect of suppression was marginally significant $(\beta=.27, t=1.67, p=.099)$. Regardless of their sex, suppressors were evaluated as more competent than nonsuppressors: $M=5.1(S D=1.8)$ vs $M=4.3$ $(S D=1.7), t(72)=2.11, p<.05$. The data therefore support Hypothesis 3, which states that participants who successfully hid (some of) their anxiety would be evaluated as more competent than participants who did not hide these feelings.

\subsection{Consequences of hiding feelings II: Is emotional suppression during the interview associated with more negative affect after the interview? (Hypothesis 4)}

A hierarchical regression analysis was conducted with the self-rating of depressed state in the post-interview questionnaire as the criterion variable. As possible 
predictors, the pre-interview self-rating of depressed state was entered in the first step, sex of participant and self-reported suppression were entered in the second step, and the sex $\times$ suppression interaction was entered in the last step. Results of this analysis are shown in Table 3. Pre-interview self-ratings accounted for $10 \%$ of the variance in post-interview self-ratings. Inclusion of sex and suppression in the second step led to a significant increase $(9 \%)$ in explained variance. The interaction between sex and suppression, entered in the third step, further increased the variance explained in post-interview self-ratings of depressed state by $5 \%$. In the last step of analysis, two predictors remained significant and accounted for $24 \%$ (adjusted: $19 \%$ ) of the variance in self-ratings of depressed state, namely the pre-interview self-rating of depressed state and the sex $\times$ suppression interaction. The latter finding indicates a differential effect of suppression on post-interview affective self-ratings in men and women. This interaction is illustrated in Figure 2. Male suppressors

Table 3. Hierarchical multiple linear regression analysis: predictors of post-interview self-ratings of depressed state

\begin{tabular}{llccc}
\hline Step & Predictor & $\beta_{\text {step 1 }}$ & $\beta_{\text {step 2 }}$ & $\beta_{\text {step 3 }}$ \\
\hline 1 & Pre-interview Self-rating & $.31^{* * *}$ & $.36^{* * *}$ & $.34^{* * *}$ \\
2 & Sex & & $.28^{*}$ & .06 \\
& Suppression & & $.22^{+}$ & .00 \\
3 & Sex $\times$ suppression & & & $.35^{*}$ \\
$\Delta R^{2}$ & .10 & .09 & .05 \\
$F_{\text {change }}$ & $7.72^{* *}$ & $3.90^{*}$ & $4.34^{*}$ \\
$R_{\text {cum }}^{2}$ & .10 & .19 & .24 \\
adj $R_{\text {cum }}^{2}$ & .08 & .15 & .19 \\
\hline
\end{tabular}

Note: ${ }^{+} p=.058,{ }^{*} p<.05,{ }^{* *} p<.01,{ }^{* * *} p<.001$. and nonsuppressors showed no increases in negative affect from pre- to post-interview; both groups had very low scores on self-rated depressed state both before and after the interview. In women, however, suppressors showed an increase in self-rated depressed state from pre- to post-interview, $t(12)=-3.13$, $p<.01$, whereas nonsuppressors showed no significant change, $t(23)=-75, p=.46$. Hypothesis 4 was thus supported only in female participants.

\section{Discussion}

The majority of participants (76\% of women and $78 \%$ of men) in the present study stated that their behavior in a simulated job interview was influenced by display rules (Hypothesis 1). The display rules they identified - e.g., 'Be cool!' and 'Just don't show your emotions!' - stress the importance of concealing negative feelings such as anxiety or insecurity and of presenting a self-confident image. These findings are in line with previous research on the role of assertive self-presentation in job interviews (Posthuma et al., 2002), for example, an assertive communication style (Gallois, Callan, \& Palmer, 1992). Previous research investigating the use of IM techniques in the context of employment interviews has focused primarily on verbal behavior, and not on emotion regulation. The results of the present study show that the IM techniques used in job interviews also encompass nonverbal behavior.

The second hypothesis, which states that men are more likely than women to hide negative feelings during job interviews, was also supported: more men $(n=23)$ than women $(n=13)$ said that they had tried to
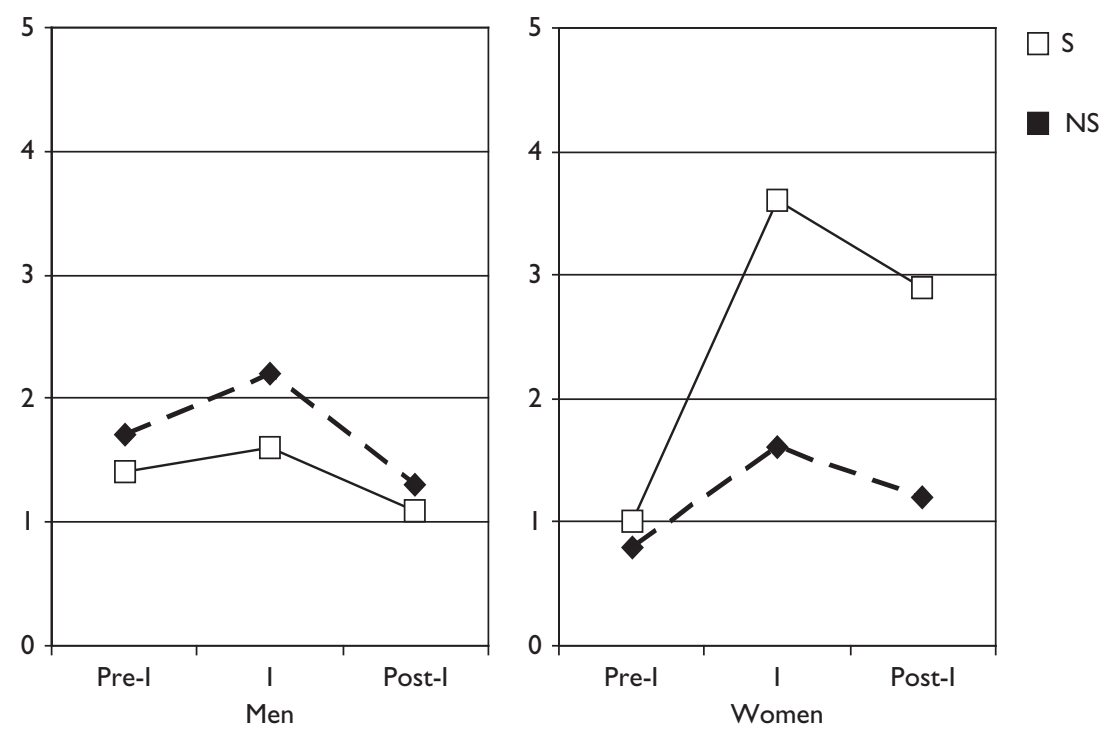

Figure 2. Self-ratings of depressed state (mean levels) as a function of suppression and sex; possible values from 0 to $9 ; \mathrm{S}$, suppressors; $\mathrm{N}$, nonsuppressors; Pre-I, pre-interview questionnaire; I, interview; Post-I, post-interview questionnaire. 
suppress or hide their feelings. The concealed emotion nominated most frequently was 'insecurity.' Although insecurity does not figure as a basic emotion in the literature on emotions, it appears to be common in social performance situations, and can be understood to encompass 'social anxiety' (Laux \& Weber, 1991). The finding that more men than women actively tried to hide their negative feelings can be explained by men's stronger socialization to suppress such emotions (Brody, 2000; Grossman \& Wood, 1993) and by reference to gender roles. For example, Jansz identified 'stoicism' as one of four focal attributes of contemporary masculinity (along with autonomy, achievement, and aggression). Stoicism involves the strict control of pain, grief, and vulnerable feelings (Jansz, 2000).

But does hiding negative feelings work in job interviews? Are suppressors indeed evaluated as more competent (Hypothesis 3)? Based on the results of this study, the provisional answer is yes. The external evaluations of two female judges who were blind to the hypotheses of the investigation validated the participants' self-reports of suppression. Based on video recordings of each participant, the judges registered less nonverbal expressiveness (fewer hand to body movements) in suppressors, and female suppressors made a less anxious impression on the judges than did female nonsuppressors. Interestingly, female suppressors described themselves as more anxious during the interview than did either female nonsuppressors or male participants. This finding supports previous research showing that there is not necessarily a positive association between self-rated and external-rated anxiety (McCarthy \& Goffin, 2004). The present study is the first to show that (some) applicants can consciously conceal (some) of their anxiety from observers. Furthermore, self-reported suppression was a significant predictor of external-rated competence: as predicted by Hypothesis 3, suppressors were externally evaluated as more competent than nonsuppressors.

The fourth hypothesis, which states that hiding feelings in a job interview has psychological costs, was supported only in female participants. Women who hid their feelings during the interview showed increased self-ratings of depressed state from pre- to post-interview; the same did not apply to women who did not hide their feelings or men (regardless of whether they hid their feelings or not). This pattern of results indicates that hiding negative emotions in job interviews may have more negative psychological effects for women than for men.

\subsection{Limitations and strengths}

Some limitations of this study warrant mention. The job interview situation was simulated in the laboratory, and the participants did not interact with real interviewers. It can be assumed that emotional expression and perceived anxiety differ in real interview situations. The laboratory setting with audiotaped instructions and videotaped responses was chosen to ensure high objectivity and standardization of the situation. Several studies have shown that interviewer behavior influences the verbal and nonverbal behavior of job applicants (Dougherty, Turban, \& Callender, 1994; Liden, Martin, \& Parsons, 1993). Had real interviewers been used, the situation would have been much more complex, and it would have been necessary to control for the behavior (both verbal and nonverbal) of the interview panel as well as the interaction with the behavior of the interviewees.

Another limitation of the study is that suppression was not experimentally manipulated; the measure was drawn from participants' self-reports in a post-interview questionnaire. Although the external evaluations validated the participants' self-reports of suppression at least partly, a more powerful design would be to compare a group of participants instructed to hide any negative feelings with a group of participants given no instructions regarding emotional expression. Similar approaches have been used in research on the physiological consequences of hiding feelings (Gross \& Levenson, 1993) and on emotional regulation and exhaustion in a call center simulation (Sideman Goldberg \& Grandey, 2007). Theoretically, a third group of participants might be instructed to express their negative feelings openly, but this approach does not seem feasible within what is intended to be an ecologically valid simulation of a job interview.

A further limitation is that applicants' nonverbal expressiveness and competence were assessed by the same raters. It cannot be ruled out that the ratings of expressiveness (which were done first) influenced the subsequent competence ratings. Another limitation concerns the assessment of the affective state in terms of a single item ('depressed'). Future research should ensure a more differentiated assessment of affective state (positive and negative). Finally, because only immediate-level responses were assessed in this study, no conclusions can be drawn about longer term impacts (Anderson \& Goltsi, 2006).

Despite these limitations, this first laboratory study to investigate the role of display rules in interviews has a number of notable strengths. An ecologically valid situation was simulated, and both self-reports and external evaluations were used. The findings provide new insights by demonstrating that emotional expression in job interviews is strongly influenced by display rules. More men than women actively tried to hide their negative feelings, and participants who hid their negative feelings were evaluated as more competent. The literature on gender differences in the socialization 
of emotion regulation (Brody, 2000) suggests that women do not learn to hide feelings of weakness as well as men. So are men the better 'role-players' in employment interviews? More research is needed to answer this question. The present results support previous findings of gender differences in IM in organizational settings (see for an overview Guadagno \& Cialdini, 2007). The study also advances knowledge on the NPEs of selection procedures for job applicants (Anderson \& Goltsi, 2006). Women who hid their negative feelings felt more depressed after the interview than did female nonsuppressors or men. These women clearly show NPEs of selection procedures in terms of 'declines in applicant psychological well-being, general mental health or core self-esteem' (Anderson \& Goltsi, 2006, p. 237). Given that this study only examined immediate reactions, however, "longer-term effects that are robust and deep-rooted' could not be demonstrated.

\subsection{Implications for research and practice}

Future research should examine the personal antecedents of applicant reactions (e.g., personal characteristics associated with an increase in negative affect). For example, are women with a more traditional female self-concept or a more traditional attitude toward gender roles more susceptible to the negative consequences of hiding feelings? Likewise, the role of personality traits should be analyzed. A previous study on the effects of workplace emotional labor on physical symptoms found that suppression of negative emotions was most strongly associated with ill health in individuals high in negative affectivity (Schaubroeck \& Jones, 2000).

Future research should further analyze whether the negative affective reactions observed in female suppressors have cognitive and/or behavioral consequences. Several studies (e.g., Gilliland, 1994) have indicated that negative experiences (e.g., unfairness perceptions) in the selection process translate into subsequent decreases in self-esteem and self-efficacy. In their detailed discussion of antecedents and consequences of applicant reactions to selection procedures, Chan and Schmitt (2004) identify possible motivational and performance implications. They propose that applicant reactions influence motivational processes, which in turn impact behavior (e.g., withdrawal or poorer performance). The experience of increased negative affect during an interview as a result of emotional suppression may have implications for the self-esteem and selfefficacy of (female) job applicants, impairing their motivation and performance in future interviews. It can be assumed that the increased negative emotions and stress experienced in a job interview can impact people's attitudes toward interviews in general and perhaps even their subsequent interview behavior (Ryan \& Ployhart, 2000). Some such negative consequences are identified in the (open) statements provided by several women in the follow-up questionnaire, who expressed stress and discomfort with the selection situation in general and with the specific display rules they felt were relevant in that situation. Whereas a number of men described the simulated job interview as a 'challenge' or an 'opportunity', several women evaluated it as a 'threat' or a 'loss', and their own performance as a 'failure':

It is quite a stressful situation when you have to say what qualifies you for the job, and to present your own strengths and qualities as well as possible. I always feel awkward in those situations, I have the impression of having to 'sell' myself, and I'm not good at that at all. ... Although I plan not to feel like a 'loser,' I feel my chances are slim from the beginning...

Another woman wrote:

It's a very uncomfortable situation for me, especially when I'm forced to say what qualifies me for the job, what my strengths are, and in what respects I'm 'better' than others ... I feel such a failure $\ldots$ and the very thought of what to expect in a job interview situation is just awful.

These quotes illustrate the average increase in depressed state reported by female suppressors immediately after the job interview, which persisted to the post-interview assessment after completion of the whole selection procedure (see Figure 2). In contrast, most men were quite pleased with their performance: 'At least I managed to keep a poker face!' Given that men are traditionally socialized to hide their negative feelings (Brody, 2000; Grossman \& Wood, 1993), men who hid their feelings in our study showed behavior consistent with the male gender role (and possibly with their normal behavior), whereas women who hid their feelings deviated from the traditional female role and potentially their normal behavior. This may explain why hiding negative feelings in a job interview has higher psychological costs for women.

The present findings have several practical implications. When display rules in a job interview situation demand the concealment of negative feelings such as insecurity or anxiety, women may well be at a disadvantage in the selection process, and selection fairness (Truxillo, Steiner, \& Gilliland, 2004) may be reduced. Another possible outcome may be the withdrawal of qualified women from the selection process. Anderson (2004) described the costs to organizations that result from the withdrawal of potentially high-level job performers. Withdrawal would certainly also have psychological costs for the women who abstain from fulfilling career opportunities. This raises the question of how to shape selection interviews that give male and 
female applicants the same opportunities to present their qualities and strengths.

As it is not realistic to expect any substantial change in the latent display rules governing job applicants' behavior in selection interviews, however, a more pertinent question may be the following: Is it possible to learn how to 'be cool' without psychological costs in a job interview? If yes, special training programs particularly for women - could be developed and evaluated. For example, it might be helpful for women to consider a key issue of IM mentioned by the 'founder' of the dramaturgical approach, Erving Goffman. Life is like a theatre, and we each perform to others, with a view to influencing their impression of us (Goffman, 1959). If women can (learn to) see the selection process and the interview more as a play or a challenge than as a threat, the negative consequences of emotional suppression may well be lessened or eliminated.

\section{Acknowledgements}

The author would like to thank Bettina von Volkmann for carrying out the laboratory study and Birgit Herbeck for suggestions in designing the expressiveness scales and for training the judges.

\section{Notes}

1. The data analyzed in this study stem from a broader dataset that has formed the basis for three previous articles (Sieverding, 2000, 2003; Sieverding, Weidner, \& von Volkmann, 2005). The articles overlap in only some of the variables used and address different research questions.

2. A total of 92 students participated in the assessment. Of these, 18 were excluded from the analyses, 17 because of missing data resulting from equipment or software failure, and one because the participant was too old (45 years).

3. The criteria for a high competence score were as follows: participant names a job-relevant weakness that is not too serious and reports that he or she has already worked to overcome/succeeded in overcoming this weakness and/or can demonstrate that this weakness is, at the same time, a strength.

\section{References}

Alexander, F. (1939) Emotional Factors in Essential Hypertension: Presentation of a tentative hypothesis. Psychosomatic Medicine, 1, 173-179.

Anderson, N. (2004) Editorial - The Dark side of the Moon: Applicant perspectives, negative psychological effects
(NPEs), and candidate decision making in selection. International Journal of Selection and Assessment, 12, 1-8.

Anderson, N. and Goltsi, V. (2006) Negative Psychological Effects of Selection Methods: Construct formulation and an empirical investigation into an Assessment Center. International Journal of Selection and Assessment, 14, 236-255.

Brody, L.R. (2000) The Socialization of Gender Differences in Emotional Expression: Display rules, infant temperament, and differentiation. In: Fischer, A.H. (ed.), Gender and Emotion: Social psychological perspectives. New York, NY: Cambridge University Press, pp. 24-47.

Brody, L.R. and Hall, J.A. (2000) Gender, Emotion, and Expression. In: Lewis, M. and Haviland-Jones, J.M. (eds), Handbook of Emotions (2nd edn). New York, NY: Guilford Press, Pp. 325-414.

Butler, E.A., Egloff, B., Wilhelm, F.H., Smith, N.C., Erickson, E.A. and Gross, J.J. (2003) The Social Consequences of Expressive Suppression. Emotion, 3, 48-67.

Chan, D. and Schmitt, N. (2004) An Agenda for Future Research on Applicant Reactions to Selection Procedures: A construct-oriented approach. International Journal of Selection and Assessment, 12, 9-23.

Cook, K.W., Vance, C.A. and Spector, P.E. (2000) The Relation of Candidate Personality with Selection-Interview Outcomes. Journal of Applied Social Psychology, 30, 867-885.

Diefendorff, J.M. and Richard, E.M. (2003) Antecedents and Consequences of Emotional Display Rule Perceptions. Journal of Applied Psychology, 88, 284-294.

Dougherty, T.W., Turban, D.B. and Callender, J.C. (1994) Confirming First Impressions in the Employment Interview: A field study of interviewer behavior. Journal of Applied Psychology, 79, 659-665.

Ekman, P. and Friesen, W.V. (1975) Unmasking the Face: A guide to recognizing emotions from facial clues. Englewood Cliffs, $\mathrm{NJ}$ : Prentice-Hall.

Fletcher, C. (1991) Candidates' Reactions to Assessment Centres and their Outcomes: A longitudinal study. Journal of Occupational Psychology, 64, 117-127.

Friedman, H.S., Hall, J.A. and Harris, M.J. (1985) Type A Behavior, Nonverbal Expressive Style, and Health. Journal of Personality and Social Psychology, 48, 1299-1315.

Gallois, C., Callan, V.J. and Palmer, J.-A.M. (1992) The Influence of Applicant Communication Style and Interviewer Characteristics on Hiring Decisions. Journal of Applied Social Psychology, 22, 1041-1060.

Gilliland, S.W. (1994) Effects of Procedural and Distributive Justice on Reactions to a Selection System. Journal of Applied Psychology, 79, 691-701.

Gilmore, D.C. and Ferris, G.R. (1989) The Effects of Applicant Impression Management Tactics on Interviewer Judgments. Journal of Management, 15, 557-564.

Goffman, E. (1959) The Presentation of Self in Everyday Life. Garden City, NY: Doubleday.

Gross, J.J. (2002) Emotion Regulation: Affective, cognitive, and social consequences. Psychophysiology, 39, 281-291.

Gross, J.J. and Levenson, R.W. (1993) Emotional Suppression: Physiology, self-report, and expressive behavior. Journal of Personality and Social Psychology, 64, 970-986.

Grossman, M. and Wood, W. (1993) Sex Differences in Intensity of Emotional Experience: A social role interpreta- 
tion. Journal of Personality and Social Psychology, 65, 10101022.

Guadagno, R.E. and Cialdini, R.B. (2007) Gender Differences in Impression Management in Organizations: A qualitative review. Sex Roles, 56, 483-494.

Hall, J.A. (1990) Nonverbal Sex Differences: Accuracy of communication and expressive style. Baltimore, MD: Johns Hopkins University Press.

Herbeck, M.-B. (1995) Charisma und Maske; Die Expressivitaet von Maedchen und Jungen in der Pubertaet [Charm and Mask: The expressivity in girls and boys during puberty]. Unpublished doctoral dissertation, University of Ulm, Germany.

Higgins, C.A. and Judge, T.A. (2004) The Effect of Applicant Influence Tactics on Recruiter Perceptions of Fit and Hiring Recommendations: A field study. Journal of Applied Psychology, 89, 622-632.

Hochschild, A.R. (1983) The Managed Heart: Commercialization of human feeling. Berkeley, CA: University of California Press.

Jansz, J. (2000) Masculine Identity and Restrictive Emotionality. In: Fischer, A.H. (ed.), Gender and Emotion: Social psychological perspectives. New York, NY: Cambridge University Press, pp. 166-186.

Kacmar, K.M., Delery, J.E. and Ferris, G.R. (1992) Differential Effectiveness of Applicant Impression Management Tactics on Employment Interview Decisions. Journal of Applied Social Psychology, 22, 1250-1272.

Kring, A.M. and Gordon, A.H. (1998) Sex Differences in Emotion: Expression, experience, and physiology. Journal of Personality and Social Psychology, 74, 686-703.

Laux, L. and Weber, H. (1991) Presentation of Self in Coping with Anger and Anxiety: An intentional approach. Anxiety Research, 3, 233-255.

Liden, R.C., Martin, C.L. and Parsons, C.K. (1993) Interviewer and Applicant Behaviors in Employment Interviews. Academy of Management Journal, 36, 372-386.

Maccoby, E.E. (1998) The Two Sexes: Growing up apart, coming together. Cambridge, MA: Belknap Press/Harvard University Press.

McCarthy, J. and Goffin, R. (2004) Measuring Job Interview Anxiety: Beyond weak knees and sweaty palms. Personnel Psychology, 57, 607-637.

Posthuma, R.A., Morgeson, F.P. and Campion, M.A. (2002) Beyond Employment Interview Validity: A comprehensive narrative review of recent research and trends over time. Personnel Psychology, 55, 1-81.

Richards, J.M. and Gross, J.J. (1999) Composure at Any Cost? The Cognitive Consequences of Emotion Suppression. Personality and Social Psychology Bulletin, 25, 1033-1044.

Richards, J.M. and Gross, J.J. (2000) Emotion Regulation and Memory: The cognitive costs of keeping one's cool. Journal of Personality and Social Psychology, 79, 410-424.

Riggio, R.E. and Friedman, H.S. (1983) Individual Differences and Cues to Deception. Journal of Personality and Social Psychology, 45, 899-915.

Ryan, A.M. and Ployhart, R.E. (2000) Applicants' Perceptions of Selection Procedures and Decisions: A critical review and agenda for the future. Journal of Management, 26, 565606.
Rynes, S.L. and Gerhart, B. (1990) Interviewer Assessments of Applicant 'Fit': An exploratory investigation. Personnel Psychology, 43, 13-35.

Saarni, C. (1979) Children's Understanding of Display Rules for Expressive Behavior. Developmental Psychology, 15, 424 429.

Schaubroeck, J. and Jones, J.R. (2000) Antecedents of Workplace Emotional Labor Dimensions and Moderators of their Effects on Physical Symptoms. Journal of Organizational Behavior, 21, 163-183.

Sideman Goldberg, L. and Grandey, A.A. (2007) Display Rules Versus Display Autonomy: Emotion regulation, emotional exhaustion, and task performance in a call center simulation. Journal of Occupational Health Psychology, 12, 301-318.

Sieverding, M. (2000) "Alle wahren Gefühle verbergen und mit fester Stimme und wohlformulierten Sätzen glänzen!” - Die Bedeutung von Selbstdarstellungsregeln im Bewerbungsinterview [The Role of Display Rules in a Job Interview Situation]. Zeitschrift für Arbeits- und Organisationspsychologie, 44, 152-156.

Sieverding, M. (2003) Frauen unterschätzen sich: Selbstbeurteilungs-Biases in einer simulierten Bewerbungssituation [Women Underevaluate Themselves: Self-evaluation-biases in a simulated job interview]. Zeitschrift für Sozialpsychologie, 34, 147-160.

Sieverding, M., Weidner, G. and von Volkmann, B. (2005) Cardiovascular Reactivity in a Simulated Job Interview: The role of gender role self-concept. International Journal of Behavioral Medicine, 12, 1-10.

Stevens, C.K. and Kristof, A.L. (1995) Making the Right Impression: A field study of applicant impression management during job interviews. Journal of Applied Psychology, 80, 587-606.

Timmers, M., Fischer, A.H. and Manstead, A.S.R. (1998) Gender Differences in Motives for Regulating Emotions. Personality and Social Psychology Bulletin, 24, 974-985.

Traue, H.C. (1989) Gefuehlsausdruck, Hemmung und Muskelspannung unter sozialem Stress; Verhaltensmedizin myogener Kopfschmerzen [Emotional Expression, Inhibition and Muscle Tension Under Social Stress. Behavioral Medicine of Myogenic Headache]. Goettingen: Hogrefe.

Traue, H.C. and Pennebaker, J.W. (eds). (1993) Emotion Inhibition and Health. Ashland, $\mathrm{OH}$ : Hogrefe \& Huber Publishers.

Truxillo, D.M., Steiner, D.D. and Gilliland, S.W. (2004) The Importance of Organizational Justice in Personnel Selection: Defining when selection fairness really matters. International Journal of Selection and Assessment, 12, 39-53.

Wallbott, H.G. and Scherer, K.R. (1991) Stress Specificities: Differential effects of coping style, gender, and type of stressor on autonomic arousal, facial expression, and subjective feeling. Journal of Personality and Social Psychology, 61, 147-156.

Young, M.J., Behnke, R.R. and Mann, Y.M. (2004) Anxiety Patterns in Employment Interviews. Communication Reports, 17, 49-57. 